\title{
La poesía es un diálogo con los muertos... Entrevista a Julián Axat
}

Poetry is a dialogue with dead people. Interview to Julián Axat

\author{
FERNANDO REATI \\ GEORGIA UNIVERSITY · freati@gsu.edu
}

DOI: 10.7203/KAM.6.7282

ISSN: 2340-1869

Julián Axat es un poeta argentino, editor de libros y abogado defensor de menores nacido en 1976 en La Plata, una ciudad a hora y media de Buenos Aires conocida por su importante universidad y por haber sido en los años 70 uno de los principales bastiones de las luchas obrero-estudiantiles, objeto por ello más tarde de una brutal represión durante la dictadura militar de 1976-1983. Sus padres, Rodolfo Jorge Axat y Ana Inés Della Crocce, militantes de la organización político-militar Montoneros, fueron secuestrados en abril de 1977 y tras permanecer unos meses en el centro clandestino de detención La Cacha en La Plata se sumaron a la larga lista de los desaparecidos. Julián, de apenas 7 meses en ese entonces, fue criado por familiares y hoy es padre de dos hijas.

Como poeta, es autor de una obra ya extensa que incluye Peso formidable (2004); servarios (2005); médium (2006); ylumynarya (2008); Neo (El equipo forense de sí) (2012); musulmán o biopoética (2013); y Rimbaud en la CGT (2014). Editó una antología, Si Hamlet duda le daremos muerte (2010), que recopila textos de 52 poetas argentinos nacidos a partir de los 70. Otra antología que editó, La Plata Spoon River (2014), recoge textos de poetas que homenajean a las víctimas de una gran inundación que asoló la ciudad de La Plata en abril de 2013, con el saldo de una centena de muertos. Sus poemas se han traducido al francés, el inglés y el portugués. Desde 2005 dirige la colección de poesía Los detectives salvajes en la editorial La talita dorada que publica, como se anuncia en la solapa de sus libros, "poesía inédita, perdida, escondida y silenciada por efecto del terrorismo de estado”, incluyendo la obra inédita de jóvenes desaparecidos en los 70 y la de sus hijos hoy. 
En el ámbito profesional, es abogado y fue profesor de derecho político en el Colegio Nacional de La Plata. En un artículo que publicó sobre los juicios que se siguen llevando a cabo por los crímenes del terrorismo de Estado, en particular el juicio correspondiente al centro clandestino La Cacha donde estuvieron secuestrados sus padres y donde él es parte querellante ("Legitimidad de los juicios de lesa humanidad", Página/12, 3/9/2015), Axat menciona el origen de su vocación por el derecho: "nuestro padres no tuvieron la posibilidad de defensa. Por eso, muchas veces pienso que quizás quise ser abogado por esa ausencia, por ese vacío del terror, por ese intento imaginario de viajar al pasado a defender lo que entonces estaba obturado y ahora no".

Axat se desempeñó en La Plata como defensor oficial del Fuero de Responsabilidad Penal Juvenil, siendo su tarea la defensa de jóvenes pertenecientes a sectores carenciados y puestos en situación de internación o cárcel por delitos o por uso de droga, en particular en aquellos casos de "gatillo fácil” en que la policía mató a jóvenes sospechados de delinquir o incluso los hizo desaparecer extrajudicialmente. Actualmente, está a cargo de un programa de la Procuración General de la Nación que brinda a la comunidad un acceso rápido y eficiente a los servicios de asesoramiento jurídico. A través de la creación de oficinas en villas miseria y barrios carenciados, denominadas Agencias Territoriales de Acceso a la Justicia (ATAJO), este programa permite que los ciudadanos más vulnerables cuenten con la ayuda de abogados, psicólogos y trabajadores sociales.

En varios artículos y entrevistas, Axat se ha referido a su trabajo con esos sectores vulnerables como parte de su oposición al "discurso de la inseguridad”. Ese discurso, difundido en ciertos medios de comunicación y alentado por algunos sectores políticos, criminaliza a los pobres, llama a endurecer las leyes penales y a aumentar la presencia policial, promueve la industria de la protección del hogar (cámaras, alarmas, guardias privados), clama por la reducción de la edad de punibilidad de los delincuentes y, en definitiva, propone la "mano dura" y la "tolerancia cero" como únicas soluciones a la conflictividad social. Si en Europa y en Estados Unidos los inmigrantes, negros y latinos son los chivos expiatorios objeto del estereotipo y la criminalización, en Argentina -afirma Axat- ese lugar lo ocupan los pobres, y en especial los jóvenes de barrios marginales que son permanentemente hostigados por la policía. Por eso la importancia que le asigna a programas comunitarios como los que él dirige, para a través de la educación, la asistencia y la divulgación de los derechos ciudadanos "despolicializar" (su neologismo) el tratamiento del delito a fin de verlo menos como una cuestión penal y más en su dimensión social.

Los artículos que Axat publica regularmente en periódicos y revistas hablan de sus variados intereses: además de cuestiones poéticas cuando se trata de la aparición de uno de sus libros, o de lo que tiene que ver con la memoria y los juicios por derechos humanos, están las problemáticas del narcotráfico, los linchamientos, los casos de justicia por mano propia y el trato de menores por parte de la 
policía y las cárceles. En la entrevista que sigue, se refiere con su habitual capacidad a la vez analítica e introspectiva a estas cuestiones.

FERnANDo ReATi. Cuando uno googlea tu nombre y encuentra artículos, comentarios y entrevistas sobre tu obra de poeta, tu trabajo como abogado defensor de menores, tu tarea de editor de libros o tus ensayos periodísticos, casi siempre hay un listado de definiciones que incluye: hijo de desaparecidos, poeta, editor, docente, abogado. ¿Hay un orden particular que, en tu opinión, se ajusta mejor a cómo te ves a vos mismo? ¿Un poeta hijo de desaparecidos o un hijo de desaparecidos poeta? ¿Un abogado poeta o un poeta abogado? Entre tantas definiciones ¿qué constituye lo sustantivo y qué lo calificativo o adjetival? ¿O simplemente no importa porque ningún rótulo prima sobre los otros?

JULIÁN AXAT. Hay un orden que se está estableciendo con el tiempo, supongo. Mi identidad se fue construyendo a la vera de un contexto social y político, pero también familiar e íntimo. Comencé siendo un simple adolescente de clase media que un día se hizo cargo de su historia como hijo de desaparecidos, con una crisis importante, con una herida inicial que mi familia se encargó de contar desde un principio. Fui alguien que a los 16 o 17 años se cruzó con otros hijos de igual condición y se pudo reconocer, así creo que también nació HIJOS. Después fueron apareciendo otras identidades, la escritura de versos fue un diario de vida, la prueba gramática de un hijo que se reconocía como hijo e Hijo. Más tarde la necesidad de pensar esa escritura en verso, como un "archivo" específico que no sea cualquiera archivo, sino el propio y poético; de ahí el editor, el detective literario o salvaje el día que descubrí a Bolaño o conocí a Juan Gelman. La docencia es el punto que me conecta con los estudiantes hoy y me permite hacer un trasvasamiento de mi propia Historia a las nuevas generaciones. La abogacía es la enseñanza de mi abuelo abogado que me llevaba a su estudio jurídico a los 12 años porque no tenía con quien dejarme, y me daba una Olivetti para jugar mientras él atendía a sus clientes. Eso me llevó en algún momento a la misma profesión, a la búsqueda de mi justicia que era la historia de la injusticia de mi país basada en indultos y leyes de impunidad fabricadas con palabras de lo injusto. Y de allí a un salto en la defensa de pibes pobres, para defenderlos con palabras de lo justo, o presentarme como querellante abogado en el juicio por la desaparición de mis padres. Ha sido la palabra justa lo que me interesa, la precisa, la más bella, la maña y obsesión por la justicia poética. Por eso al final viene el Poeta, la Poesía como la identidad ordenadora de todo lo demás, de todas mis identidades. Igual no podría definirme Poeta, más bien poeta con minúsculas, formas de expresión desde la poesía con mi identidad. Soy alguien que busca y prueba disfraces, registros, experimenta como con heteronimias (servarios). Mis libros de poemas son eso, cambios de registro. El haber sido hijo de desaparecidos es una sustancia que hoy ya dejo un poco atrás, porque eso me enrola-cristaliza en una suerte de víctima que ahora quiero dejar de ser o de la que me quiero correr. El terror que no se va te fija en esa única condición. No hay más primacía que una forma de estar en el mundo militando con el cuerpo y la palabra, una potencia que busca salirse de la ontología de 
la herida inicial, para buscar un cuerpo sin un rótulo que me atrape. Me gusta moverme entre las pasiones alegres, ése es mi vitalismo de lo poético: ser un poco padre, hermano, editor, HIJO, hijo, docente, abogado, jurista, defensor, víctima, victimario, etc. Es el arte el que me ha permitido escribir poesía y ser todo esto, como una identidad política, después del horror.

FERNANDO REATI. En jAy, mis ancestros!, un libro sobre la reiteración de fobias y enfermedades entre descendientes de víctimas del Holocausto y otras situaciones traumáticas, la terapeuta francesa Anne Schützenberger señala que a menudo acarrean un resentimiento por la pesada carga de ser hijos de víctimas y sienten que es injusto lo que les tocó sobrellevar. De allí el reclamo (por lo general inconsciente) hacia los padres por haberlos puesto en esa situación. En obras producidas por hijos de desaparecidos argentinos noto a veces esa especie de reclamo, entremezclado con el amor y admiración que sienten por los padres. También veo evidencia de lo que Diana Kordon y Lucila Edelman, psicoterapeutas que han trabajado con familiares de las víctimas, consideran un sentimiento inconsciente de abandono: ¿por qué mis padres me abandonaron al desaparecer? ¿Por qué eligieron la revolución y no me eligieron a mí? En un intercambio de correos electrónicos que tuvimos, me dijiste que admiras a tus padres por "la alucinación de abandonarme por un sueño que es también mío, aunque anacrónico". ¿Alguna vez te enfrentaste a esa sensación de abandono y hasta de posible resentimiento por la vida que te tocó llevar? Si fue así, ¿cómo conciliaste ese sentimiento con el amor y la admiración que sientes hacia tus padres por su entrega generosa a una causa?

JULIÁN AXAT. Yo siempre escribí muy seguido el mismo poema. Mi respuesta es la poesía. Es el poema XXX del libro Peso formidable que escribí a los 19 años, hoy es la reescritura del poema "Hamlet Hubieras" de mi último Rimbaud en la CGT. Es un sueño reiterativo, como el dialogo con los desaparecidos-muertos. Viajo al pasado y me encuentro con mis padres, tenemos la misma edad, se inicia una discusión acalorada. Faltan un par de horas y los milicos están por caer. Ustedes o yo. Juntos nos vamos de acá. Ese es el dilema. Yo los rescato o los dejo. ¿Qué van a hacer? Desde muy chico tengo ese sueño. La forma en que se resuelve el sueño-poema es distinta cada vez, y tiene que ver con mi crecimiento interno. Hay veces que luego de fuertes discusiones políticas, ellos me abrazan y se despiden igual, diciéndome que no. Ellos se quedan, son obstinados. ¿Eligen desaparecer? ¿El hijo puede rescatar a los padres? ¿Ellos me rescatan a mí? Hubo un tiempo de culpa en todo esto, supongo. Hoy el poema es una interpelación política, las noches que mi padre se queda y lo rescato, le pregunto cómo me hubiera criado de no haber desaparecido, cómo hubiera sido como abuelo o si hubiera cobrado una pensión por ex guerrillero jubilado. Y hasta lo increpo preguntándole si pediría mano dura para los delincuentes que yo defiendo como defensor de pobres... No hay rechazo o resentimiento. Hay un enojo desafiante, provocador, pero es ternura al fin. Hay más bien tristeza por la pérdida pero también hay dialogo generacional inconcluso, cortado. Hay enseñanza de cierto coraje, hay ejemplo y donación de una 
herencia a descifrar. Hay rebeldía mutua. Los textos de Kordon y Edelman parecen haber sido pensados para estructuras psíquicas con evidencias de un hijo neurótico. En mi caso eso está, claro, pero también está la imaginación, el arte, la poesía, y eso excede los textos clásicos de la psicología del trauma tras un genocidio. Esos encasillamientos se caen ante el ejercicio del arte político que trabaja tu dolor. Muchos de nosotros redimimos esa culpa por no tenerlos y la sublimamos con el arte que elegimos.

FERnANDO REATI. Cuando desaparecen los padres, el diálogo intergeneracional se ve abruptamente interrumpido. Lo mismo ocurre con la rebeldía juvenil contra los padres, que en el caso de los hijos de desaparecidos no se puede dar porque es imposible discutir con un ausente: ¿cómo se pelea con un muerto? Como me señaló alguna vez Emiliano Fessia, hijo de desaparecidos y director del Espacio de Memoria en el ex centro clandestino de detención La Perla, la desaparición deja suspendida la discusión porque lo que falta es el padre para putearlo. Otro poeta hijo de desaparecidos y amigo tuyo, Nicolás Prividera, escribe que es como si al desaparecido "lo hubieran puesto en pausa hace treinta años”. En tu caso, ¿has lidiado con esa imposibilidad de discutir y putearte con tus padres? ¿Constituye la poesía un medio para llevar a cabo esa discusión imposible?

Julián AXAT. Absolutamente. Como te decía, yo dialogo con mi papá y mi mamá todo el tiempo. La poesía tal como yo la concibo es un diálogo con los muertos. Este tema me obsesiona desde hace mucho. La poesía es para mí una suerte de sesión de espiritismo, un espacio de acá para el más allá, como una cisura del encuentro. Hace casi dos años armé una antología (La Plata Spoon River) que busca dialogar con los muertos víctimas de la inundación de mi ciudad, tomando el método del poeta americano Edgar Lee Masters, el epitafio en primera persona. Ese libro no pudo haber nacido sino de mi constante obsesión con dialogar con mis padres y hallar mensajes en esos diálogos para poder seguir. También en musulman o biopoética, utilicé el dialogo con los adolescentes que yo defendía y que asesinó la policía. Ellos hablan desde algún lugar, se quejan, yo recojo sus lamentos y los poemas son quejas políticas de víctimas de la violencia institucional. La búsqueda de las voces de los muertos hay que hallarla dentro de las voces de uno: "dejen que las voces de los muertos en nosotros, tomen la palabra” (es la cita con la que abro mi libro Médium). Pienso por ejemplo en el texto de Daniel Tarnopolsky sobre la desaparición de su hermana Betina, no soy el único al que le pasan estas cosas... Los desaparecidos están muertos pero en una zona distinta a otros, ellos están en el aire, son fantasmas que todavía perciben la violencia que los llevó; somos los vivos los que los mantenemos a flote transformados en energía; la función del poeta tal como yo la concibo es agudizar los sentidos para hacerlos hablar, para dialogar, pero también para discutir, provocarlos y ayudarlos a irse. La escritura es un trance ante el vacío, los fantasmas y el símbolo de los padres como generación diezmada. Un pase de magia o de psicomagia que nos ayude a nosotros a dejar de ser víctimas también. 
FERNANDO REATI. Schützenberger llama “parentización” al fenómeno por el cual se quiebra el sistema normal de deudas intergeneracionales: ante la victimización de los padres, los hijos "se convierten en padres de sus propios padres". En Neo pareces proponer una nueva genealogía donde los roles se invierten. En un poema dices: "Padre: / hijo / que ejerce / oficio de padre. / Hijo: / padre / que ejerce / oficio de hijo". En otro relatas ese sueño en el que te encuentras con tu padre justo antes de que vengan a secuestrarlo y tratas de convencerlo de que huya pero no lo logras, sintiéndote de algún modo responsable de su suerte: "te ruego la huida / vamos lejos / bien lejos te digo / pero me contestás que... / la sangre de los compañeros no se negocia / y no hay caso / Padre / no te convenzo / la escena se repite muchas noches / llegamos a discusiones acaloradas / y no hay caso / Padre / no puedo salvarte ni en los sueños". Pareces sugerir que tu padre fue incapaz de salvarse a sí mismo y quisieras ayudarlo adoptando el rol adulto que él de algún modo no tuvo. Cuando te pregunté en un correo electrónico por ese poema, respondiste: "puedo proteger a mi padre, porque me da tristeza profunda su historia y su sangre derramada, quiero contenerla o hacerle un torniquete, abrazarlo, quiero ser el padre de mi padre, porque mi padre ya es un niño para mí y yo defiendo a esos niños...” Al declarar como testigo en el juicio por el centro clandestino La Cacha donde estuvieron tus padres, dijiste: "hubiera querido defender a mis padres, ser esa defensa que ellos no tuvieron..." Y en Rimbaud en la CGT escribes: "Soñé que viajaba al pasado / Y que un milico me decía / vamos a permitir que seas el defensor de tus padres / antes de que desaparezcan..." ¿Te sientes padre de tus padres, especialmente ahora que has sobrepasado la edad que ellos tenían cuando murieron? ¿Defender como abogado a jóvenes delincuentes y marginados es una manera de adoptar ese rol paterno que hubieras querido tener para con tus padres indefensos?

JULIÁN AXAT. El arte de la defensa en general es distinto al de la ofensa. Aprender a defenderse es un arte que impide la herida, nos escuda, neutraliza el dolor y el daño. Uno se defiende a sí mismo o acepta la defensa de otro. La defensa de un otro suele asumirse como acto natural, así la defensa de un padre o una madre a un hijo. Es decir, una buena defensa es un acto filial del fuerte con el débil. Cualquier régimen o comunidad mínimamente organizada, aun cuando es gobernada con el brazo del autoritarismo y persigue a sus enemigos, deja un resto de defensa antes de la ejecución formal o informal. El terror y el genocidio borran ese mínimo de civilización que exige al menos testear la posibilidad de error ante quien se considera enemigo; es decir, al enemigo se le da un mínimo de derecho a defenderse. Mis padres fueron secuestrados y torturados, luego asesinados de un tiro en la cabeza. Nunca hubo posibilidad mínima de defensa ante el genocida, ni siquiera en una farsa de juicio. Esto siempre me obsesionó y me lleva a pensar la categoría del defensor jurídico en términos metafísicos y poéticos. Por eso fui defensor oficial de pobres durante ocho años. Y por eso la poesía siempre es un arte que está allí para hablar de los vencidos, los muertos y oprimidos. Desde ya que creo que mis padres se defienden políticamente solos y no puedo juzgar sus convicciones, las que creo eran muy fuertes. En todo caso, sin subestimar su entrega, nace en mí la obsesión de una defensa que eleve o potencie sus ideas. Entre mis 
viajes al pasado a dialogar con mis padres, también sueño que los milicos me dan una concesión (imposible) de un juicio en el que yo encarno en el mejor abogado y soy un abogado maldito, un poeta maldito del contra-terror que los intenta salvar de la ejecución. En ese rol en el que se confunde mi presente real como defensor de adolescentes considerados hoy como si fueran "terroristas", aparece el juego de que mis padres podrían haberse encarnado en ellos como otros "terroristas"; pero también la idea de que yo soy el padre de mi madre y mi padre, y cumplo una función de abogado y poeta protector. El hijo que salva a sus padres como si fueran sus hijos, y de ese modo se salva a sí mismo. (Al ver la foto de mis padres ellos son dos adolescentes eternizados en esa etapa, yo ya les llevo más de diez años). La poesía y el derecho son mis armas frente a la ofensa del Mal. Las inversiones hijo-padre son parte de mis búsquedas y encuentros Hamletianos con la sombra. Por último, te quiero aclarar que acá en la Argentina los represores y genocidas tienen muy buenas defensas, ya sea porque se las pagan o porque tienen buenos defensores oficiales que los tratan como presos políticos, de allí que la legitimidad de los juicios de derechos humanos descanse en eso que esta gente no les dio a nuestros padres, algo que hoy el sistema legal les garantiza a ellos, el derecho de defensa. El día que declaré como testigo lo dije mirando a los ojos a los defensores, mis colegas: "ustedes hacen lo que yo hubiera querido hacer con mis padres, ejercer su defensa". Aun a sabiendas de que no los iba a poder rescatar, en la defensa se diferencia el pasado y el presente; y por eso no hay reconciliación posible como pretenden ciertos sectores, porque el terror borró la mínima defensa. Entonces, para terminar, la poesía se convierte en la defensa por otros medios, que ya no son jurídicos.

Fernando Reati. En Identidades desaparecidas. Peleas por el sentido en los mundos de la desaparición forzada (2011), el sociólogo Gabriel Gatti, hijo y hermano de desaparecidos, dice que la lucha de los organismos de derechos humanos y las políticas oficiales del estado para investigar, reparar y lograr justicia tienen el efecto no deseado de condenarlo a él, en cuanto familiar de desaparecidos, a ser siempre definido por esa condición y ninguna otra: "Paradoja: buscando sacarme de ahí no me dejan irme de ahí, del lugar del familiar". Gatti se rebela contra esa definición limitante y defiende su derecho a dejar de ser visto solamente como "hijo de" ¿ ¿Te sientes reflejado en esa opinión?

JULIÁN AXAT. Bueno, no sé si podría atribuir esa cristalización de una identidad a la lucha de los organismos. En todo caso, sí a cierto problema de la memoria monumentalista, más que a una política de la memoria movimientista, de la tensión y el conflicto. Al respecto tengo este poema inédito: "Está de moda ser víctima / dijo un poeta / para luego hacerse la víctima / de un grupo de poetas / que lo blasfemaban / y decían que sus sonetos / apestaban a la herida / de quien no tiene un motivo / más que la impostura / de una memoria marcial / 'está de moda hacerse la víctima' / dijo otro de la tertulia / que lo corrigió / y terminaron chocando las copas / entre poetas que no lo blasfemaban / y yo solo miraba de lejos / con la farsa del victimario...” También me resulta interesante cierta lectura de Irving Goffman 
cuando trabaja la idea de "Estigma". La función de la vulneración o la herida es también la de lograr invertir la carga negativa que ésta trae consigo. Así como una discapacidad puede engendrar un plus de derechos o una discriminación inversa hacia las personas con capacidad plena. En el plano simbólico los familiares de desaparecidos suelen estar (con justa razón) en un “estado de deuda” a saldar por parte del Estado y del resto de la sociedad argentina que no ha padecido el terror o ha sido su cómplice. Muchos de los hijos de desaparecidos han sido conscientes de este lugar de víctima y lo han aprovechado (no digo instrumentalmente) en su favor, en un contexto de reivindicación como el actual. De ese modo, han logrado reparar muchas cosas que en otro contexto como el Menemato o el de la Alianza no eran pensables-reivindicables, pues el estado de víctima era la desolación-resistencia frente a la impunidad y el olvido. Le diría a Gatti que en este contexto pruebe con el arte y no con la sociología, ¡es el arte la clave! El registro del arte que permite sublimar esa condición cristalizada de "familiar" y de "hijo de". El cine, la música, la literatura, el teatro, la poesía hechas por los "hijos de”. En mi caso, ya juzgados y condenados los asesinos de mis padres, la posibilidad de jugar a ser otro desde la poesía, siento, es más viable que antes.

FERNANDO REATI. Gatti califica el hecho traumático de la desaparición como una "catástrofe del sentido" pero sostiene que, contra lo que podría suponerse, es un lugar "habitable”. Si bien la pérdida de los seres queridos es una hecatombe brutal y apabulladora, se puede construir identidad allí: "La catástrofe vino para quedarse, no se supera, no se reemplaza. Se gestiona”, dice. Interpreto que es otra manera de referirse a la necesidad de salirse del lugar de víctima y dejar de ser solamente "hijo de". ¿Sientes que la desaparición de tus padres es una catástrofe "habitable", o que con el paso del tiempo puede llegar a serlo?

JULIÁN AXAT. Es una catástrofe habitable. Mi adolescencia fue bastante inhabitable, por eso supongo me puse a tantear una escritura íntima, a hacer un diario de poesía de lo que me estaba pasando que, a la vez que me aliviara sacando sensaciones, me permitiera mantener un dialogo con las voces que tenía alrededor: mi tía, mis abuelos, mis primos, mis compañeros del colegio que me miraban raro... Necesitaba dar con cierta voluntad de poder, con un vitalismo que fuera como una tabla de naufragio. Así apareció la poesía en mi vida y así nació Peso formidable, mi primer libro, una suerte de "Diario de un Hijo" que quiere hablar con sus padres ausentes, usando voces de "otros" prestadas, incluso las de poetas que leía con obsesión y hasta plagiaba (el libro tiene reescrituras de al menos quince poetas). El paso de un Peso "insoportable" a otro "formidable" está tomado de la teoría del eterno retorno de Nietzsche en la Gaya Ciencia: “... el eterno reloj de arena de la existencia será vuelto de nuevo y con él tú, polvo del polvo... pero acaso te aniquilaría la pregunta: ¿Quieres que el instante se repita una e innumerables veces? ¡Pesaría con formidable peso sobre tus actos, en todo y por todo! ¡Cuánto necesitarás amar entonces la vida y amarte a ti mismo para no desear otra cosa que esta suprema y eterna 
confirmación!” Quien se queda en la catástrofe se ahoga, se paraliza, se suicida, se agarra cáncer. El poema que escribí en musulmán o biopoética que resume lo que te estoy diciendo es el siguiente: "Nadando en el exterminio hallaras / la palabra 'exterminio' / debajo otra vez la hallarás / y así / en todas las capas del exterminio / seguirás como poseso / hasta dar con el último gusano / la perla no exterminada que / llevarás a tu garganta de un sorbo / para procurar / un nuevo decir...". Es mi arte poética. El tiempo y la búsqueda de "ese decir” hace mi vida (cuerpo y palabra) habitable.

FERNANDO REATI. Marianne Hirsh acunó el término "posmemoria" para referirse a la reconstrucción del trauma que hace la segunda generación en base a lo transmitido por la generación que lo vivió en carne propia. Pero en el caso de los hijos de desaparecidos pareciera haber no tanto posmemorias cuanto memorias directas del trauma que ellos mismos experimentaron cuando eran bebés o niños pequeños y se llevaron a sus padres. Cuando declaraste en el juicio por La Cacha, dijiste: "Nuestros cuerpos de algún modo percibieron o sintieron esto que hicieron las patotas [grupos paramilitares]. Si yo tenía 7 meses y lloré, el sólo hecho de haber estado ahí me hace ser un testigo legítimo y ello revalida la posición de los hijos en este juicio”. ¿Es más importante para vos rescatar la memoria de tus padres o la memoria de tu propia victimización?

Julián AXAT. Yo soy testigo directo. Viví en carne propia con siete meses. Y eso se lo dije a los jueces, pero también me lo dije a mí mismo. También se lo estaba diciendo a esa concepción como la de Hirsh que aquí he leído en textos de Beatriz Sarlo. Hubo momentos que relativicé ese lugar, el del Hijo testigo, pero el tiempo y el conocimiento de mí mismo me llevaron a esa noche del 12 de abril de 1977, a esa habitación de un departamento donde quedé por un momento solo sobre una cama llorando, mientras todos eran encapuchados y se los llevaban. Somos testigos hasta donde los perdimos, después los únicos testigos serían mis padres (eso también se lo dije al tribunal, pensando en el verdadero testigo de Auschwitz que evoca Primo Levi). El año pasado me separé de mi pareja y decidí ir a vivir a ese departamento solo, a dormir y encerrarme en esa misma habitación en la que lloré y me desgarraron. Lo hice mientras se desarrollaba en paralelo el juicio. Lo hice para ver si experimentaba algo y así lo podría llevar a mi declaración... Por entonces tuve muchos sueños y aluciné cosas. Mi memoria es extraña, a veces, con recovecos. Finalmente escribí un libro: Rimbaud en la CGT (diario del encierro en el departamento de la desaparición). No rescato la memoria de mis padres ni la de mi victimización, eso ya sería un cliché. Busco nombrar lo que me pasó a mi manera, con mi arte, y sin seguir la senda-pose del martirio del hijo-Hijo. Ya no doy ni quiero dar vueltas sobre la herida. Soy otro (Rimbaud). Defendiendo jurídicamente a adolescentes pobres soy otro, así reivindico cosas que no necesariamente nombran a mis padres ni me ponen en el lugar de víctima. Abriendo una oficina de justicia en una villa miseria recupero una lucha desde "otro" lugar. Leyendo poesías en homenaje a las víctimas de una inundación ante una multitud en una plaza pública colmada, indago otra forma de la memoria, "soy otros muertos". En todo 
esto está presente el puente generacional, la potencia legada subyacente que yo quise y quiero buscar para dar con el armado de mi identidad.

FERnANDo Reati. Adorno dijo que la poesía no es posible después de Auschwitz. Pero en Neo afirmas: "Antes de Auschwitz habrá poesía / Después de Auschwitz habrá poesía / Dentro de la poesía habrá Auschwitz”. Parafraseando aquel concepto y aplicándolo al lenguaje jurídico, hace un par de años publicaste un artículo, “¿Cómo escribir Derecho después de la ESMA?”, donde insinúas que el Derecho es una gran "ficción" cuyo lenguaje se usa como instrumento de control y disciplina de sectores sociales díscolos (los pobres y marginales), y que tu tarea de abogado es construir un nuevo lenguaje jurídico. En una entrevista reciente dijiste además que llevas años analizando el lenguaje de los expedientes y que el Derecho "es mala literatura". Y en tus artículos hablas de la molestia que te ocasionan ciertas técnicas deshonestas de los abogados defensores de los procesados por crímenes de lesa humanidad para entorpecer y dilatar los juicios. Los entrecruzamientos entre tu praxis poética y tu praxis jurídica son evidentes. ¿Cómo ves esa imbricación entre los lenguajes de la poesía y el derecho, y dentro de ella tu papel de poeta/jurista?

JULIÁN AXAT. Hace poco escribí este otro poema que juega con el anterior que vos mencionas, se titula "Slavoj Zizek y Raphael Lemkin discuten sobre el origen del Mal”, y dice: “... Detrás del genocidio / un poeta genocida suscribe su partitura de versos / y una legión de jueces genocidas / que las ejecuta como sentencias para escuadrones / Del otro lado del genocidio / un poeta que sueña / organizando la resistencia de sus versos / la pasión de los revolucionarios y sus cuartillas como espadas políticas que lo siguen y sabotean escuadrones y sentencias del poeta genocida / En el centro de ese genocidio / sin tomar partido / La Poesía / la tensión en el vacío / un manto de piedad inverosímil / el ojo descuartizado de... / Dios...” El derecho instrumental es un ente. Adolf Eichman cumpliendo su deber es el ejecutor de las normas (jurídicas) de la maldita enfermiza poesía del Tercer Reich. No un poeta maldito, un mal poeta, un artista impostor como era Hitler. La categoría de los “derechos humanos" es la conquista de lo humano, el bien como respeto del “otro". El lugar del aura de las palabras donde está la fuente de la vida no instrumentalizable por el derecho neutro (positivo, lógico, aséptico, por mero deber de obediencia). Maldigo el derecho concebido como lujo para los neutros (aquí invierto el apotegma de Celaya y lo llevo al mundo jurídico) y ejecutado por los juristas y poetas neutros como autómatas y burócratas fungibles. El aura de las palabras es lo que mueve al mundo y a la acción (la praxis poética-jurídica se parecen en algún punto). La ficción jurídica es poética que hace bien o hace mal a los cuerpos. La que hace mal es siempre un ente, es mera validez, una pasión triste, tanática, hija del Mal. La que hace bien es la legítima, la que emancipa a los débiles y oprimidos. Es una pasión alegre. El "nuevo derecho" es el que está escrito con las voces de los muertos por obra de la injusticia, y solo busca ayudar a los vivos a liberarse para que no les pase lo que les pasó a los muertos. La verdadera justicia y la poesía (la 
pasión por la justicia poética) siempre buscan el lado de los vencidos, de los masacrados, de los que ocupan el lugar de la resistencia. La romántica es esto, una defensa de la poesía. Aquí vas a encontrar un artículo que escribí sobre este tema tan apasionante: “El derecho a la poesía”. También aquí: "El daño a la cultura".

FERNANDO REATI. El título de tu libro musulmán o biopoética juega con el concepto de biopolítica y también, supongo, con el término "musulmán” que en los campos de exterminio nazi designaba a quienes estaban resignados a morir: el cuerpo humano convertido en materia dispensable, excedente, vida que no merece ser vivida. En musulmán o biopoética los protagonistas son jóvenes delincuentes o percibidos como tales por la policía y los jueces, a quienes la sociedad da la espalda confinándolos en cárceles e institutos en lugar de buscar reintegrarlos. Víctimas de las políticas de "gatillo fácil" y criminalización de la pobreza, se los estigmatiza por "portación de rostro" y por verse diferentes al patrón clasemediero predominante. Tu poesía, tu trabajo de abogado y tus artículos en defensa de los jóvenes vulnerables desnudan el entrecruzamiento entre las víctimas del terrorismo de Estado y las víctimas hoy de un sistema jurídico y económico injusto. ¿Cómo ves esa continuidad entre los objetivos sociales y económicos de la dictadura y el sistema neoliberal que le siguió? ¿Qué han logrado las políticas de inclusión del gobierno kirchnerista, y qué falta todavía por hacer?

JULIÁN AXAT. Veo un corte y reconfiguración del poder entre la dictadura y la democracia, en especial frente a la idea de enemigo. El delincuente subversivo es parte de la doctrina de la seguridad nacional que en democracia, frente al poder punitivo del Estado, se despolitiza y reconfigura en delincuente común, propio de la doctrina de la seguridad ciudadana en la que entran como enemigos los jóvenes pobres de las periferias urbanas. El encarcelamiento preventivo de estas poblaciones da cuenta de un patrón de funcionamiento del sistema capitalista actual para regular los desechos de las políticas neoliberales como si se tratara de vertederos a controlar o estados de excepción, donde el estatuto de ciudadanía del derecho común se pierde. No digo nada nuevo, Michel Foucault y luego Giorgo Agamben, más acá Pilar Calveiro, trabajaron estos temas en detalle. La violencia institucional actual es una espiral cuya trama se encuentra en la precarización del empleo con alto impacto en trayectorias de migrantes, personas de color, mujeres y niños, y miembros de pueblos originarios. En las zonas de penumbra no hay siquiera encarcelamiento, sino "gobierno del musulmán": estado de zombie, la desciudadanización es la muerte gestionada por fuerzas de seguridad o grupos paraestatales con control territorial. Aquí me refiero a las víctimas del gatillo fácil, de ejecuciones extrajudiciales, de la trata y el reclutamiento para el narcotráfico y las organizaciones criminales. Claro que esto está lejos de Auschwitz o la ESMA pero sí es un estado larvario del Mal que se reproduce en democracia como violencia institucional bastante sistémica. Yo no podría comparar esto con la Dictadura Militar sin caer en una banalización, por eso me abstengo de hacer analogías aun cuando use-exporte el concepto de musulmán- 
homo sacer. En todo caso, el poder en juego es distinto, por lo tanto la defensa es otra y la poesía (la mía) o el ejercicio del derecho será otro/a. Como defensor de adolescentes criminalizados me ha tocado desplegar acciones de ruptura para demostrar la injusticia del sistema, teniendo a veces logros y otras pérdidas. Es un placer demostrarle al sistema sus contradicciones haciendo de abogado del bien. Claro que en Argentina el panorama no resulta igual que en México o Brasil donde la violencia institucional es intensa y el número de encarcelados y muertos a manos de las fuerzas de seguridad es muchas veces escandaloso. En Argentina en los últimos años hubo avances que van a contrapelo de las políticas neoliberales de los 90, el tejido social se recompuso gracias a medidas de intervención estatal como la Asignación Universal por Hijo o el Plan Progresar que impulsaron a niños y jóvenes que estaban a la deriva a continuar sus estudios y mejorar su estado sanitario. Sin embargo, este impacto virtuoso presentó una paradoja. Las fuerzas de seguridad locales y nacionales han mantenido su autogobierno autoritario y no han sido democratizadas a fondo, por lo que existen en su interior imaginarios bélicos que conllevan la regulación del delito y la criminalización de estos jóvenes aun cuando cobren subsidios o estén incluidos en algún programa estatal (me ha tocado defender a jóvenes que percibían asignaciones). Sin presentar los niveles de violencia de otros países de Latinoamérica, la violencia institucional con inclusión social es una contradicción del sistema o una nueva reconfiguración del poder en Argentina. Ante ambas posibilidades hay que buscar una manera de neutralizar este daño y reformular el Estado de derecho para que los más débiles vivan dignamente y en paz. Estoy seguro de que el pos-kirchnerismo presentará todo el tiempo esta tensión, veremos si lo resuelve o echa más nafta al fuego acrecentando cada vez más el poder de las fuerzas de seguridad sin replantear su control civil y su democratización interna.

FERNANDO REATI. Una última pregunta relativa al futuro. En 2016 cumples 40 años y también es el 40 aniversario del golpe militar. No mucho después serán 40 años de la desaparición de tus padres. Cuatro décadas no es poco. ¿Crees que algo va a cambiar tras esas fechas en cuanto a cómo la sociedad piensa a los hijos de los desaparecidos? ¿Y en cuanto a tu autoimagen, especialmente ahora que eres padre de dos hijas?

Julián AXAT. Creo que el juzgamiento a los militares está avanzando, también de a poco el juzgamiento de la complicidad civil, como política de Estado y ya no de un gobierno. La pregunta está en la complicidad económica. ¿Cuándo yo cumpla 40 habrá juzgamiento del hecho económico que llevó a la dictadura? Sería un regalo hermoso para mis 40... Pero mejor pensarlo como una lucha, como algo que debemos conquistar, no como un obsequio a nosotros mismos. Ver sentados en el banquillo a los responsables de Loma Negra, Acindar, Blaquier, Clarín, Perez Companc, etc. Parece un salto histórico, un deseo hermoso, difícil de que se cumpla. "Toda poesía es hostil al capitalismo”, decía Gelman. Como te decía en la respuesta anterior, el panorama político que se avecina en Argentina cierra por derecha y 
será un escenario muy complejo. Los juicios de derechos humanos son una bisagra, una forma de cierre de la herida, una respuesta a las víctimas y un ejemplo para el mundo. Mi autoimagen, la que deseo al menos, no es ya la de un hijo de desaparecidos filial, como era antes, haciendo un escrache o pensando la estrategia de un juicio con otros hijos filiales. Es la de cualquier hijo de este pueblo que interpela por sentirse parte y dolido más allá de ser el "hijo de”. Deseo mis 40 años como la despedida del disfraz de Hamlet generacional 76, de ciertos sueños reiterativos, de visitas de los murmullos nocturnos... La despedida de una generación de armadores de rompecabezas filial, una generación de hijos perdidos, menores, parias, buscadores, tan detectives salvajes como dice Roberto Bolaño. 